\title{
Methods for determination of ultimate load of eccentrically patch loaded steel I-girders
}

\section{Métodos para la determinación de la carga última en vigas de acero en I sometidas a una carga concentrada excéntrica}

\author{
B. Šćepanović $^{(*)}$, M. Knežević ${ }^{(*)}$, D. Lučić ${ }^{(*)}$
}

\section{ABSTRACT}

Experimental tests show that most eccentrically patch loaded steel I-girders have a collapse mode quite different from that of centrically loaded girders. Concerning engineering practice, the most important difference between collapse modes is in ultimate load. The reduction in ultimate load with an increase in load eccentricity is obvious in some eccentrically loaded girders. Under certain circumstances, for a certain combination of influential parameters, eccentrically loaded girders behave as if loaded in the web plane, with no or no significant reduction in ultimate load due to load eccentricity. Dealing with such a big number of mutually dependant parameters that influence collapse mode and level of ultimate load reduction due to load eccentricity, still without theoretical formulation of collapse mechanism, two approaches for ultimate load determination are analysed: empirical mathematical expressions and artificial neural networks forecast models. Results of two procedures are compared. Recommendations for application in engineering practice are given.

Keywords: Steel I-girder; eccentric patch load; ultimate load; empirical expression; ANN forecast model.

\section{RESUMEN}

Las pruebas experimentales muestran que la mayoría de vigas en I de acero cargadas excéntricamente tienen un modo de colapso muy diferente del de las vigas cargadas centradas. En cuanto a la práctica de ingeniería, la diferencia más importante entre los modos de colapso es la carga final. La reducción de la carga última con un aumento de la excentricidad de carga es evidente en algunas vigas cargadas excéntricamente, mientras que bajo ciertas circunstancias, para una determinada combinación de parámetros influyentes, las vigas cargadas excéntricamente se comportan como si se carga en el plano del alma, con ninguna reducción significativa en la carga última debido a la carga excéntrica. Se analizan dos métodos para la determinación de la carga máxima: expresiones matemáticas empíricas y redes neuronales artificiales. Los resultados de ambos procedimientos se comparan. Se dan recomendaciones para su aplicación en la práctica.

Palabras clave: Vigas de acero en I; carga excéntrica; carga última; expresión empírica; modelo de pronóstico ANN.

(*) University of Montenegro, Podgorica (Montenegro).

Persona de contacto/Corresponding author: biljazs38@gmail.com (B. Šćepanović)

Cómo citar este artículo/Citation: Šćepanović, B., Knežević, M., Lučić, D. (2014). Methods for determination of ultimate load of eccentrically patch loaded steel I-girders. Informes de la Construcción, 66(EXTRA-1): mo18, doi: http://dx.doi.org/10.3989/ic.13.076.

Licencia / License: Salvo indicación contraria, todos los contenidos de la edición electrónica de Informes de la Construcción se distribuyen bajo una licencia de uso y distribución Creative Commons Reconocimiento no Comercial 3.o. España (cc-by-nc). 


\section{INTRODUCTION}

Patch loading acts locally, over a small area or length of a structural element. It is a common situation in structural engineering that local compressive load affects the flange of steel I-girder so that the web is compressed in the region below the applied load. Local stresses in the vicinity of load might cause local instability that may provoke element carrying capacity loss and, consequently, collapse of the whole structure. This is rather complex and challenging issue of extremely evident elasticplastic stresses and deformations. Apart from that, geometrical nonlinearity is noticeable even at the lowest loading level.

Patch loaded girders (Figure 1) are widely used and present in different structures, including crane girders loaded by crane wheels or bridge girders during launching.
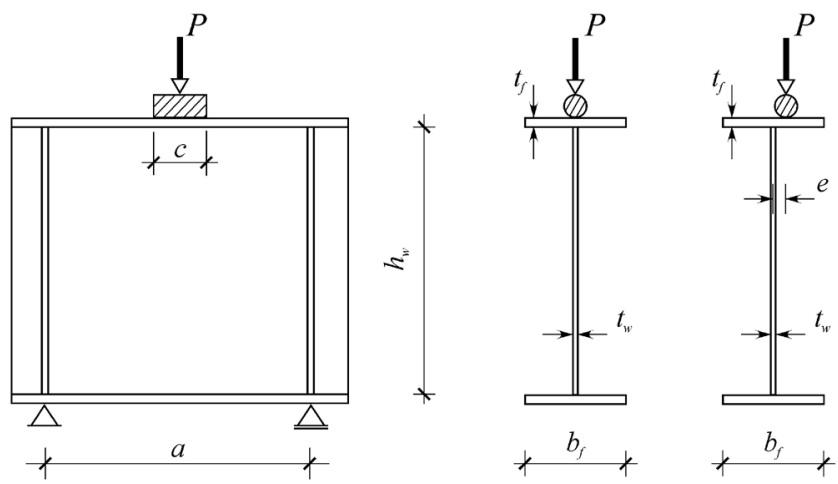

Figure 1. Patch loaded I-girder - centric and eccentric patch loading.

Although some eccentricity of load relative to the web plane is unavoidable in engineering practice, rather modest amount of worldwide research work has treated this issue in comparison with the amount of worldwide research work that have treated centric patch loading. While over 35 experimental researches (with more than 750 tested samples) dealt with I-girders patch loaded in the web plane, influence of load eccentricity was analysed in only eight experimental studies (with less than 200 tested samples) (1) (2) (3) (4) (5) (6) (7) (8) (9) (10). Experimental analysis of eccentrically patch loaded girders started at the University of Maine in late $1980 \mathrm{~s}$ (1) (2) (3). At the same time some tests were done at the Institute of Theoretical and Applied Mechanics, Czech Academy of Sciences (4). Ten years later a new series of experiments (1998, 2001, 2007) were initiated at the University of Montenegro (5) (6) (7) (8) (9) (10). The newest testing, with only four tested girders, was done at the University of Navarra, upon the initiative of the University of Granada, in 2009 (10). Experimental work was followed by finite element method (FEM) modelling, by means of various computer software (1) (2) (3) (4) (5) (6) (7) (8) (9) (10). While over 30 mathematical expressions (mostly based on collapse mechanism) for centric ultimate load might be found in literature, only few empirical expressions for eccentric ultimate load have been proposed (3) (8) (9) (10). Artificial neural networks, being suitable for multi-parameter analysis, are also used nowadays for collapse mode and ultimate load estimation (8). However, mathematical model for ultimate load calculation based on collapse mechanism, or some other theoretical approach, has not yet been proposed.

Since the first experimental investigations, in 1980s, it has been evident that numerous parameters influence the behaviour, collapse mode and ultimate load of eccentrically patch loaded steel I-girders: geometric parameters (girder's dimensions and their dimensionless ratios), load eccentricity and its relations with girder dimensions, as well as the manner of load application (line or laterally distributed load). Dominant parameter is the load eccentricity, $e$, or ratio $e / b_{f}$. Apart from this parameter, the influence of girder geometry parameters should be studied. Girder dimensions, primarily web and flange thicknesses, $t_{w}$ and $t_{f}$, as well as ratio $t_{f} / t_{w}$ are of important influence. Other ratios, like $b_{f} / t_{f}, a / t_{w}, h_{w} / t_{w}$ should be considered as well. Attention should also be paid to the load length, $c$, or ratio $c / a$ and to the load application manner. Hence, not only that influential parameters are numerous, but they are also mutually dependant and related and therefore should not be considered separately. Combinations of certain parameters should be carefully analysed.

Even 1980 s tests shown and all later experiments confirmed that most eccentrically patch loaded steel I-girders (but not all and not always!) have a collapse mode quite different from that of centrically loaded girders (Figure 2). Carrying
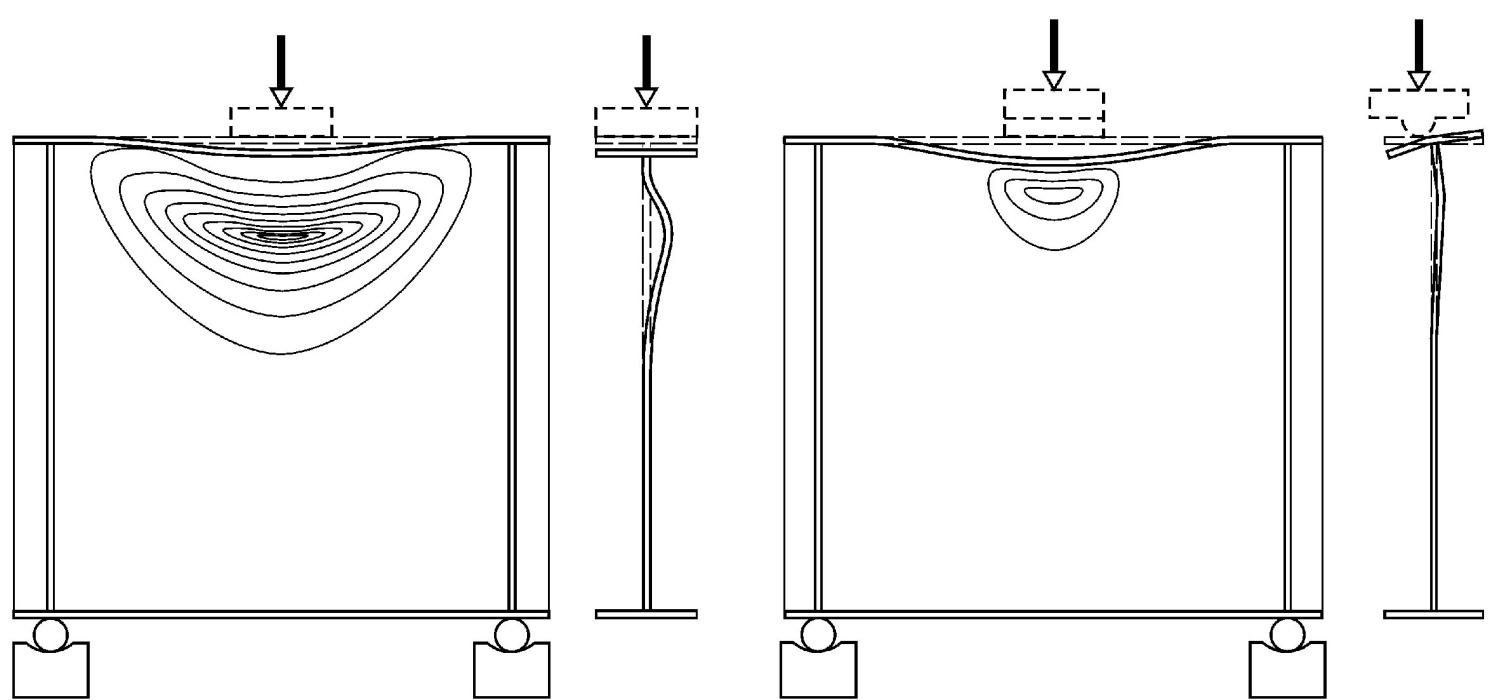

Figure 2. Collapse modes typical for centric and eccentric patch loading - centric and eccentric collapse mode. 
capacity loss in the case of centric load is due to web buckling and local stability loss (centric collapse mode, Figure 2a). In the case of eccentric load, girders lose carrying capacity due to local elastic-plastic bending (eccentric collapse mode, Figure 2b). Three different collapse modes are observed in experimentally tested eccentrically patch loaded steel Igirders: eccentric (1) (2) (5) (6) (7) (8), centric (1) (2) (5) (6) (7) (8) and mixed (8) collapse mode. Mixed collapse mode, having characteristics of both, centric and eccentric collapse modes, may appear in two variants: as centric-mixed or as eccentric-mixed collapse mode, depending on dominant collapse mode characteristics (8).

Concerning engineering practice, the most important difference between collapse modes is in ultimate load. The reduction in ultimate load with an increase in load eccentricity is obvious in girders with eccentric collapse mode. For a certain girder geometry, even the smallest load eccentricity ( $e=5 \mathrm{~mm}$, i.e. $e / b_{f}=1 / 30$ in tested girders (8); series EB VIII, EB XII and EB XVIII, Table 1) reduced ultimate load over $40 \%$. However, eccentrically loaded girders under certain circumstances, for a certain combination of influential parameters, behave as if loaded in the web plane, with no or no significant reduction in ultimate load due to load eccentricity. Even for the highest load eccentricity ( $e=25 \mathrm{~mm}$, i.e. $e$ / $b_{f}=1 / 6$ in tested girders (8); series EB I and EB XI, Table 1), girders of certain geometry behaved as if there is no eccentricity.

With such a big number of mutually dependant parameters that influence collapse mode and level of ultimate load reduction due to load eccentricity, still without formulation of collapse mechanism, two approaches for ultimate load determination are suitable: empirical mathematical expressions (3) (8) (9) (10) and artificial neural networks (ANN) forecast models (8). Both methods are based on experimental and/or FEM experience, their application is limited to cases from experimental and/or FEM data domain and every future experimental and/or FEM testing should be followed by their revision and adjusting in order to improve their accuracy.

\section{EMPIRICAL MATHEMATICAL EXPRESSIONS}

In the case of eccentric (or mixed-eccentric) collapse mode, ultimate load reduces as the load eccentricity increases (1) (2) (3) (5) (6) (7) (8) (9) (10). This decrease in the ultimate load might be expressed by a reduction factor, $R$, that relates the ultimate load of eccentrically loaded girder to the ultimate load of identical centrically loaded girder, equation [1] (3) (8) (9) (10). Ultimate load of centrically patch loaded girder might be calculated by one of numerous and very accurate existing mathematical expressions. Ultimate load of eccentrically patch loaded girder then might be easily calculated if the reduction is evaluated correctly and confidently.

$$
R=\frac{\text { ultimate load of eccentrically loaded girder }}{\text { ultimate load of centrically loaded girder }}
$$

The first published expression for the ultimate load reduction factor, $R$, is based on experimental studies conducted in 1980 s (1) (2) (3). Reduction factor is expressed in terms of two main geometric parameters: $R$ is a function of $t_{f} / t_{w}$ and varies linearly with $e / b_{f}$, equation [2] (3). Application of this formulation is limited to girders with dimensions from the range of experimental data used for expression derivation (3): $1 \leq t_{f} / t_{w} \leq 4$ and $e / b_{f} \leq 1 / 6$.

$$
\begin{aligned}
& R=m \cdot \frac{e}{b_{f}}+n<1 \\
& m=-0.45 \cdot\left(\frac{t_{f}}{t_{w}}\right)^{2}+4.55 \cdot\left(\frac{t_{f}}{t_{w}}\right)-12.75 \\
& n=1.15-0.025 \cdot\left(\frac{t_{f}}{t_{w}}\right)
\end{aligned}
$$

Recent experimental work (from 1998, 2001 and 2007), with wider range of test data (5) (6) (7) (8) (9), indicates that the original expression for $R$ should be modified. Not only that its application does not provide valid results for girders with parameters $t_{f} / t_{w}$ and $e / b_{f}$ out of range given in (3). Quality of its results is also dependant on other parameters $\left(b_{f} / t_{f}, a / t_{w}\right.$, $c / a, a / h_{w}$ ) that should be considered as limitation factors for each empirical expression application.

Join research work of teams from the University of Montenegro and Granada University resulted in several modifications of original expression for reduction factor (8) (9) (10). New, improved expressions are also empirical, obtained by regression analysis based on all available experimental data (until 2007) as well as on results of finite element modelling (FEM) by ANSYS. One of these expressions, which has very good match with the wide range of experimental and numerical data, is defined by equation [3] (8) (9). The reduction factor, $R$, is considered to be a quadratic function of the most relevant parameter $e / b_{f}$ and, same as in the original expression, dependent on the most influential geometry parameter $t_{f} / t_{w}$.

$$
\begin{aligned}
R= & m \cdot\left(\frac{e}{b_{f}}\right)^{2}+n \cdot\left(\frac{e}{b_{f}}\right)+1.01 \leq 1 \\
& m=-0.864 \cdot\left(\frac{t_{f}}{t_{w}}\right)^{2}-14.40 \cdot\left(\frac{t_{f}}{t_{w}}\right)+38.00 \\
& n=-12.30+4.22 \cdot\left(\frac{t_{f}}{t_{w}}\right)
\end{aligned}
$$

Additional requirements for values of $R$ calculated by Equation [3] are: $\mathrm{o}<R \leq 1$ and $R=1$ for $e / b_{f}=0$.

Same as any other empirical expression, equation [3] should be used only in the range of data used for regression analysis. Experimental data used for the derivation of [3] are in the following range: $1 \leq t_{f} / t_{w} \leq 5$, (o) $1 / 30 \leq e / b_{f} \leq 1 / 5,45 \leq$ $a / t_{w} \leq 233,10 \leq b_{f} / t_{f} \leq 50, c / a=0.071$ or $0.214, a / h_{w}=1$ (1) (2) (3) (5) (6) (7) (8) (9). Range of FEM (ANSYS) data used for the derivation of [3] differs: $1 \leq t_{f} / t_{w} \leq 4$, (O) $1 / 25 \leq$ $e / b_{f} \leq 1 / 6.25,117 \leq a / t_{w} \leq 233,6.25 \leq b_{f} / t_{f} \leq 25,0.036 \leq$ $c / a \leq 0.071,1 \leq a / h_{w} \leq 2$; with constants: $h_{w}=700 \mathrm{~mm}$, $t_{w}=6 \mathrm{~mm}, b_{f}=150 \mathrm{~mm}, c=50 \mathrm{~mm}$ and variables: $e(0,6,12$, $18,24 \mathrm{~mm}), t_{f}(6,12,18,24 \mathrm{~mm}), a(700,910,1050,1260$, $1400 \mathrm{~mm}$ ) (8) (9). 
Improvement of expression [3] in comparison with the expression [2] is illustrated in Figures 3, 4, 5, 6, 7, where $R_{\text {exp }}$ (ratio of experimental ultimate loads of eccentrically and centrically loaded girder, according to equation [1]), $R_{F E M}$ (ratio of FEM ultimate loads of eccentrically and centrically loaded girder, according to equation [1]) and $R_{\text {emp }}$ (calculated by equations [2] and [3]) are experimental, FEM and empirical values of reduction factor, respectively. All experimental data with load length $c=50 \mathrm{~mm}$ from 1998 (Figure 4), 2001 (Figure 5) and 2007 (Figure 6), as well as relevant experimental data from 1988 (Figure 3) are included into graphical presentation. Only one set of FEM data, with span girder $a=700$ $\mathrm{mm}$, is graphically presented (Figure 7). Diagrams for higher values of girder span, $a$, are very similar to this one, having the same shape of $R_{F E M} / R_{e m p}-e / b_{f}$ curves with slightly different numerical values, for each flange thickness, $t_{f}$. Trend of curves proximity to horizontal line corresponding to value of $1\left(R_{\text {exp }} / R_{\text {emp }} \approx 1\right.$ and $\left.R_{F E M} / R_{\text {emp }} \approx 1\right)$, i.e. better match with experimental and FEM data, is much more obvious for equation [3] than for equation [2].

It has to be pointed out that every future experimental testing or FEM modelling should be followed by new revision of empirical expression for the ultimate load reduction factor in order to improve its accuracy. Apart from that, even with the existing experimental and FEM data base, this kind of mathematical modelling is almost endless, offering almost countless options - to choose different functions for $R$, different influential parameters, their forms and combinations or different methods of expression calibration. Presented expression by equation [3] is chosen and recommended as simple and reliable for application in engineering practice.

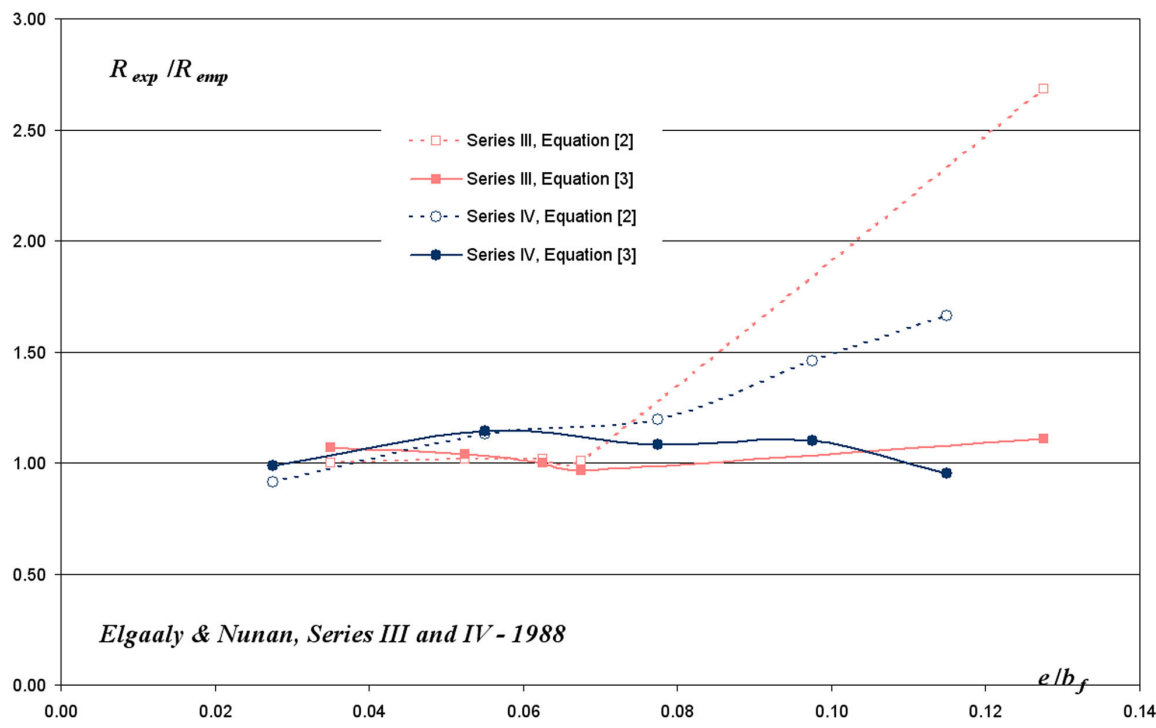

Figure 3. Comparison of experimental and empirical values of reduction factor, $R$, calculated by equations [2] and [3], for experimental data from 1988 .

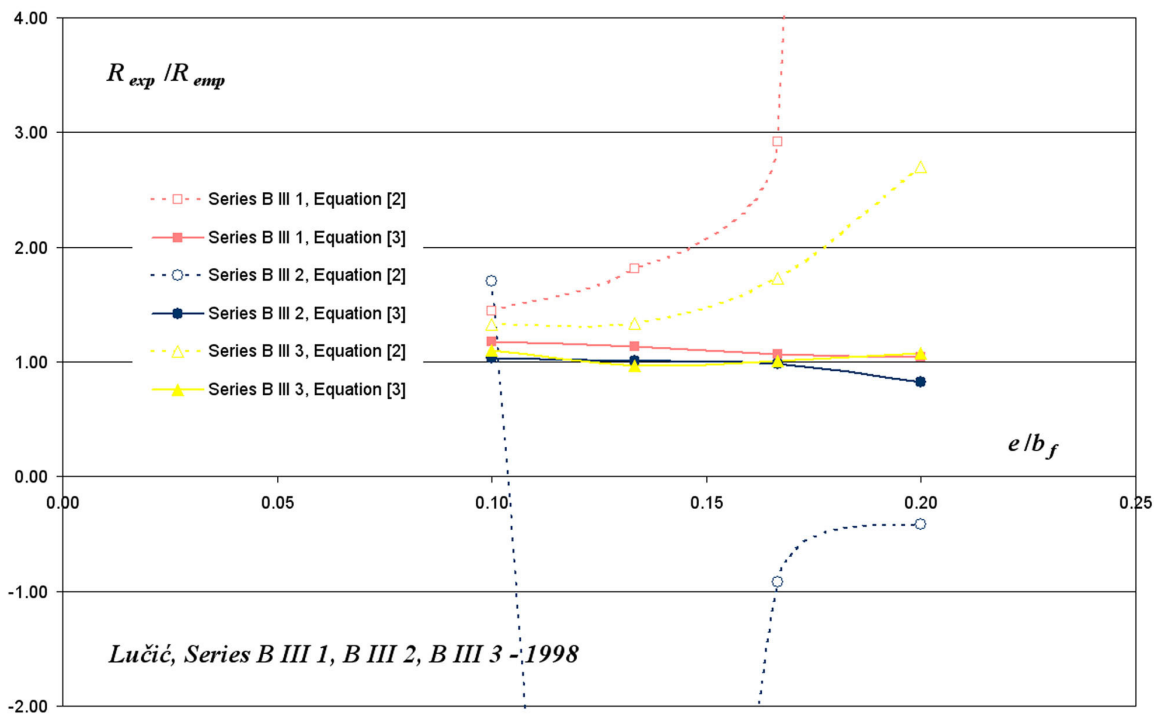

Figure 4. Comparison of experimental and empirical values of reduction factor, $R$, calculated by equations [2] and [3],for experimental data from 1998. 


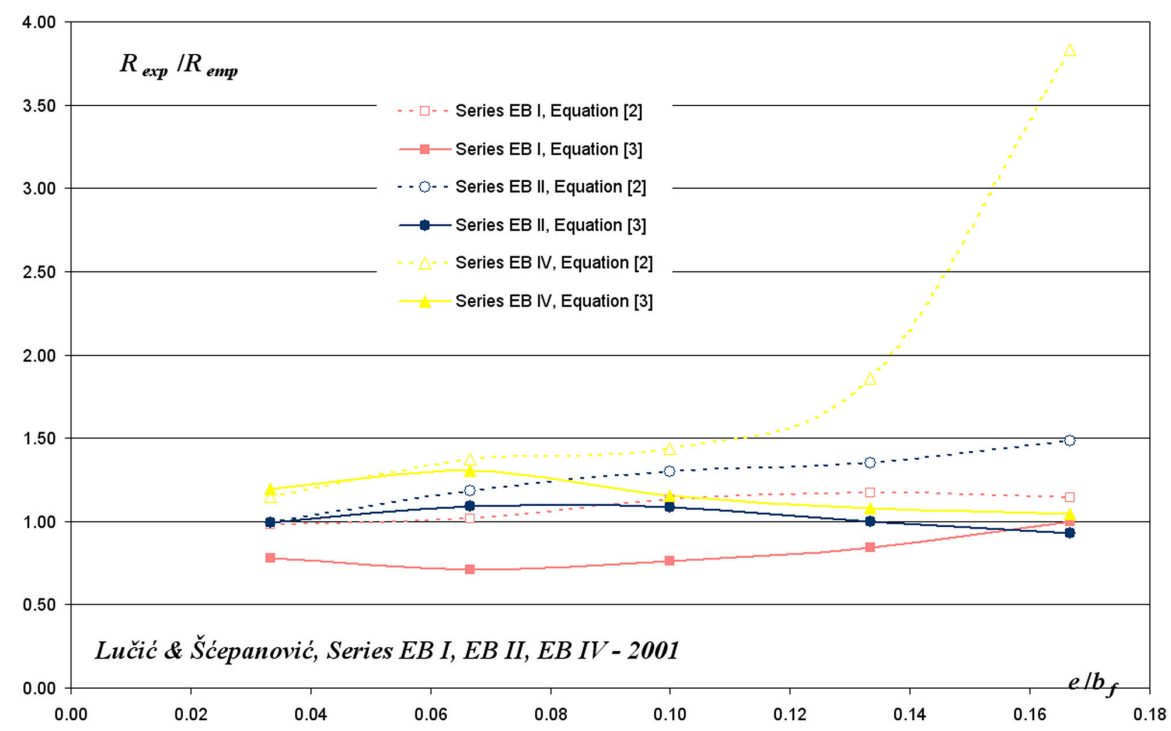

Figure 5. Comparison of experimental and empirical values of reduction factor, $R$, calculated by equations [2] and [3], for experimental data from 2001.

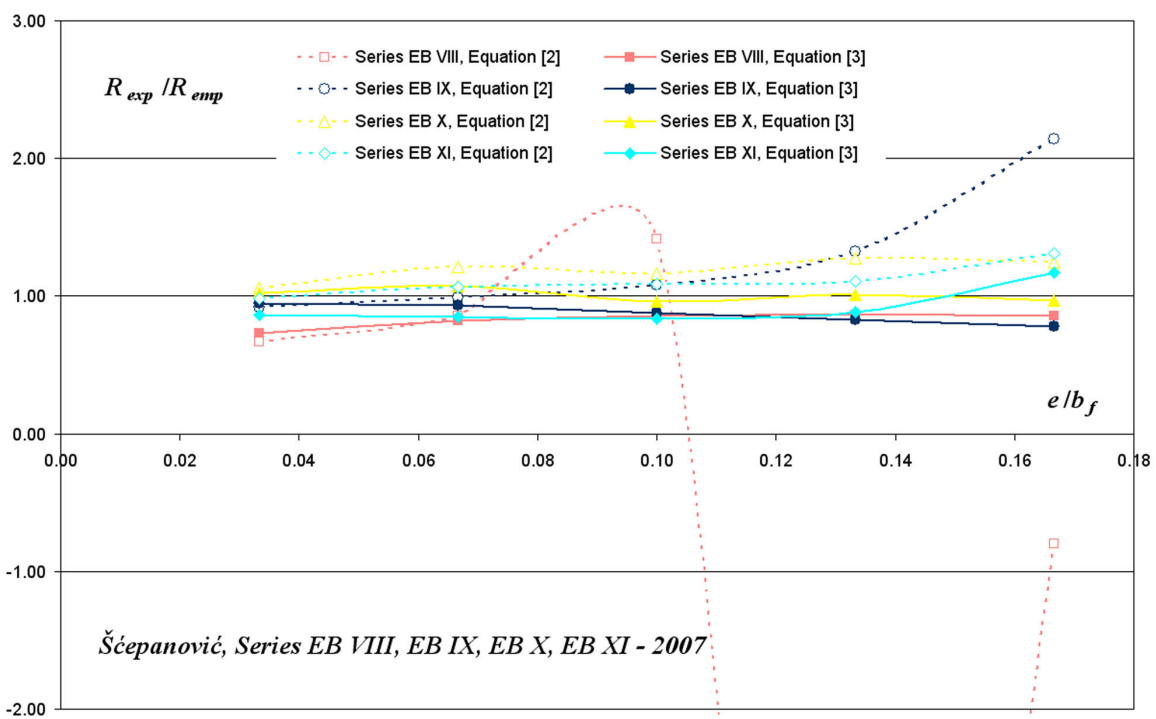

Figure 6/1. Comparison of experimental and empirical values of reduction factor, $R$, calculated by equations [2] and [3], for experimental data from $2007-$ girders with $t_{w}=3 \mathrm{~mm}$.

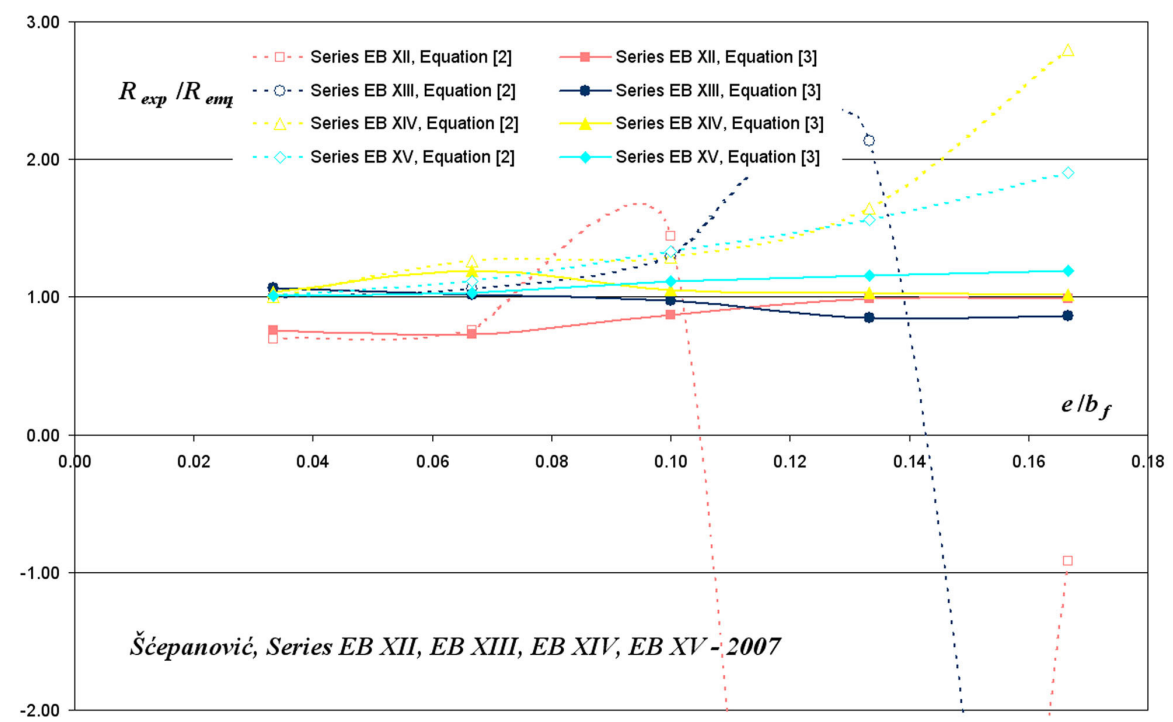

Figure 6/2. Comparison of experimental and empirical values of reduction factor, $R$, calculated by equations [2] and [3], for experimental data from $2007-$ girders with $t_{w}=4 \mathrm{~mm}$. 


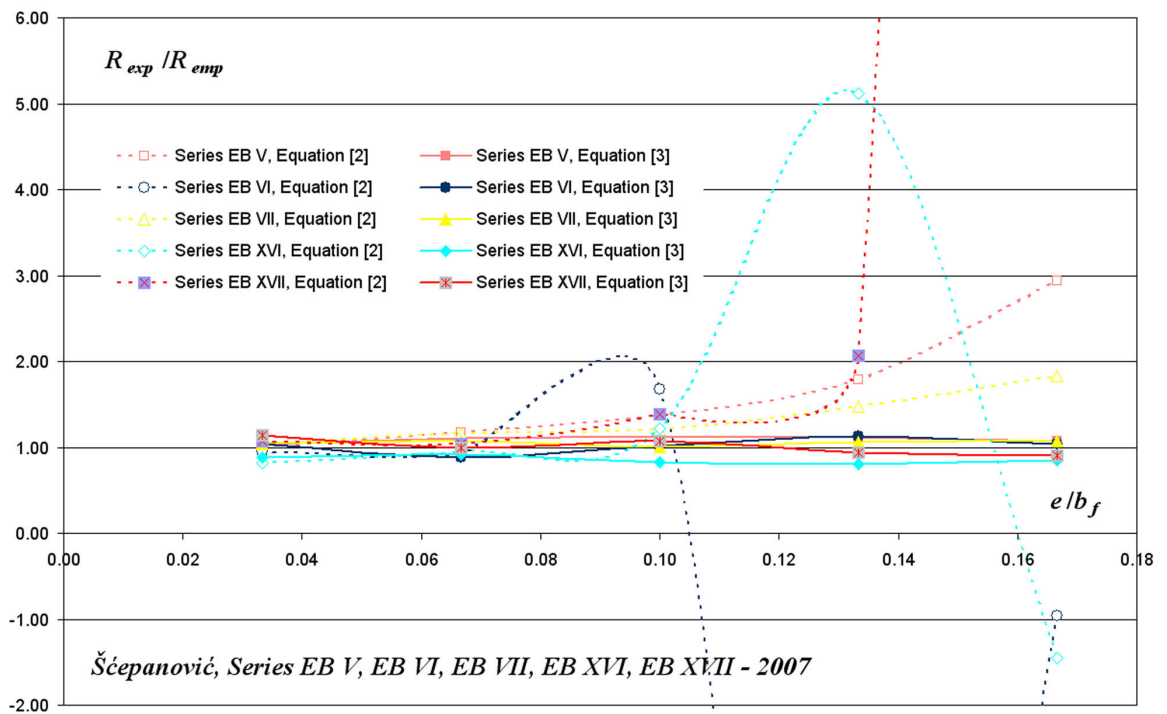

Figure 6/3. Comparison of experimental and empirical values of reduction factor, $R$, calculated by equations [2] and [3], for experimental data from $2007-$ girders with $t_{w}=5$ and $10 \mathrm{~mm}$.

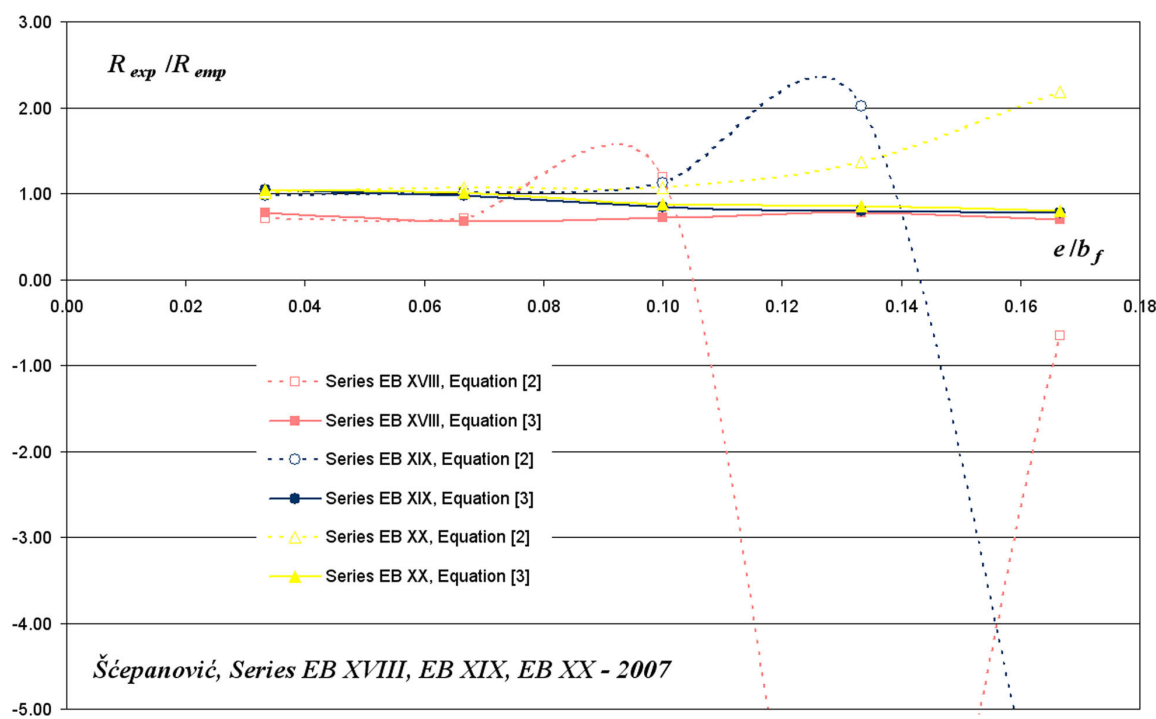

Figure 6/4. Comparison of experimental and empirical values of reduction factor, $R$, calculated by equations [2] and [3], for experimental data from $2007-$ girders with $t_{w}=6 \mathrm{~mm}$.

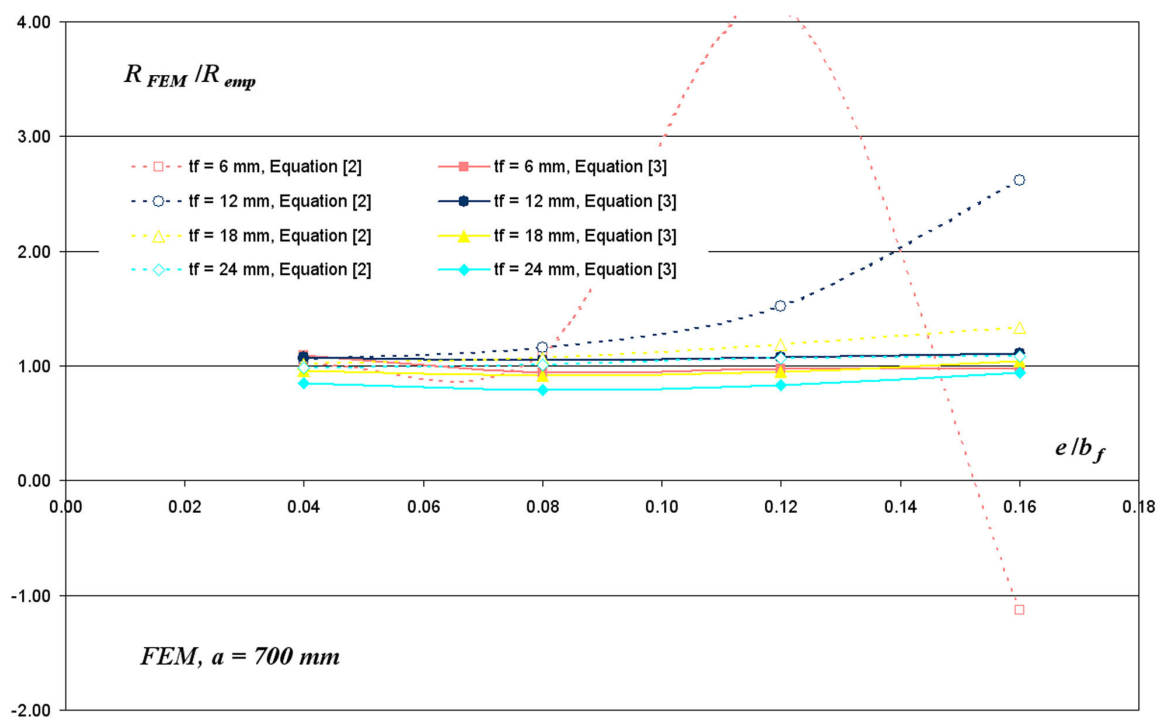

Figure 7. Comparison of FEM and empirical values of $R$, calculated by Equations [2] and [3] - girders with $a=700 \mathrm{~mm}$. 


\section{ANN FORECAST MODELS}

\subsection{Artificial neural networks (ANN) modelling method}

ANN modelling method is based on the analogy with the human nervous system (8) (9) (10) (11). Artificial neuron imitates biological neuron. Artificial neural network (ANN), consisted of artificial neurons, is computational simulation of human neural network, consisted of biological neurons. Humans use their mind to make conclusions and decisions in certain situations based on the previous (similar) experience. ANN does not have human mind and experience that should be used to process input data and make appropriate conclusions/ decisions, i.e. output. In ANN modelling method human mind is replaced by mathematical functions (as much as such replacement is possible) and human experience is replaced by existing data base which is used for ANN training. By training and validation of ANN on some data base, forecast models are created in order to estimate output parameter(s) for certain set of input parameters that is not present in the data base, but that is in the range of data base. ANN modelling method is highly suitable for multi-parameter analysis.

\subsection{ANN forecast models for collapse load}

The basic idea is to estimate the collapse load, $P_{u}$, as the only output parameter, depending on numerous input parameters (material characteristics, girder geometry and load eccentricity), as well as to asses applicability of ANN modelling method as a tool for collapse load determination in engineering practice and to compare it with more conventional method of empirical expressions (8).

Several types of forecast models were made using experimental data from 1998, 2001 and 2007: with dimensional (e.g. $e$, $t_{f}, t_{w}$ ) and dimensionless (e.g. $\left.e / b_{f}, e / t_{f}, e / t_{w}, b_{f} / t_{f}, t_{f} / t_{w}, h_{w} / t_{w}\right)$ geometry inputs. Several types of network architecture were constructed: with one or two hidden levels of neurons; with different number of neurons - 1 to 20 - in each level, depending on inputs number and number of training data. The same computer software (8) (9) (10) (11) was used for training of all created artificial neural networks. Comparison of different networks and forecast models was done in comparison data set, in order to evaluate which models provide the best forecast of collapse load.

ANN models were made separately for girders with different load lengths ( $c=50$ or $150 \mathrm{~mm}$ - two load lengths used in experiments from 1998, 2001 and 2007). Herein only load length of $c=50 \mathrm{~mm}$ and models with five dimensional inputs $\left(e, t_{w}\right.$, $t_{f}, \sigma_{0.2, w}$ - web yielding stress, $\sigma_{0.2, f}$ - flange yielding stress) and one output $\left(P_{u}\right)$ are considered. The complete experimental data set for girders with load length $c=50 \mathrm{~mm}$ consisted of 120 girders tested in 2001 and 2007, all having same dimensions $b_{f}, a$ and $h_{w}: b_{f}=150 \mathrm{~mm}, a=700 \mathrm{~mm}$ and $h_{w}=700 \mathrm{~mm} .19$ testes were exempted from the network training process and used as a comparison data set, i.e. as data for the evaluation of forecast models. The rest of 101 tests were divided in training data set (71 tests) and validation data set (30 tests).

The best evaluated models show high level of match with experimental data and prove to be acceptable for engineering practice. Particularly good results are obtained from network with two hidden levels, each with ten neurons ("c5O - load $2-10$ ") (8). Examples of collapse load forecast models of this network are presented in Figure 8 which illustrates estimation of collapse load and its relation with the load eccentricity $P_{u, a n n}(e)$ for $t_{w}=5 \mathrm{~mm}$ and different values of $t_{f}=5 \div 15 \mathrm{~mm}$, all at fixed $c=50 \mathrm{~mm}, \sigma_{o .2, w}=28 \mathrm{kN} / \mathrm{cm}^{2}$ and $\sigma_{o .2, f}=28 \mathrm{kN} /$ $\mathrm{cm}^{2}$. Some of these values of $t_{f}$ have been tested experimentally $\left(t_{f}=6,8,10\right.$ and $\left.12 \mathrm{~mm}\right)$. However, ANN models fill in the gaps for values that were not present in the experiment and also widen domain of $t_{f}$ values. Appropriate graphical presentation of $P_{u, a m n}(e)$ for fixed value of $t_{f}$ and different values of $t_{w}$ might also be created, assuming fixed values of $c, \sigma_{o .2, w}$ and $\sigma_{o .2, f}$, Figure 9. Similar estimations of collapse load and its relations with the web thickness or dimensionless parameter $t_{f} / t_{w}$, i.e. $P_{u, a n n}\left(t_{w}\right)$ or $P_{u, a n n}\left(t_{f} / t_{w}\right)$, might be made, as well. Such diagrams proved to be interesting, leading to various and important conclusions.

It is important to point out that ANN forecast models provide reliable output only for input data from the domain of

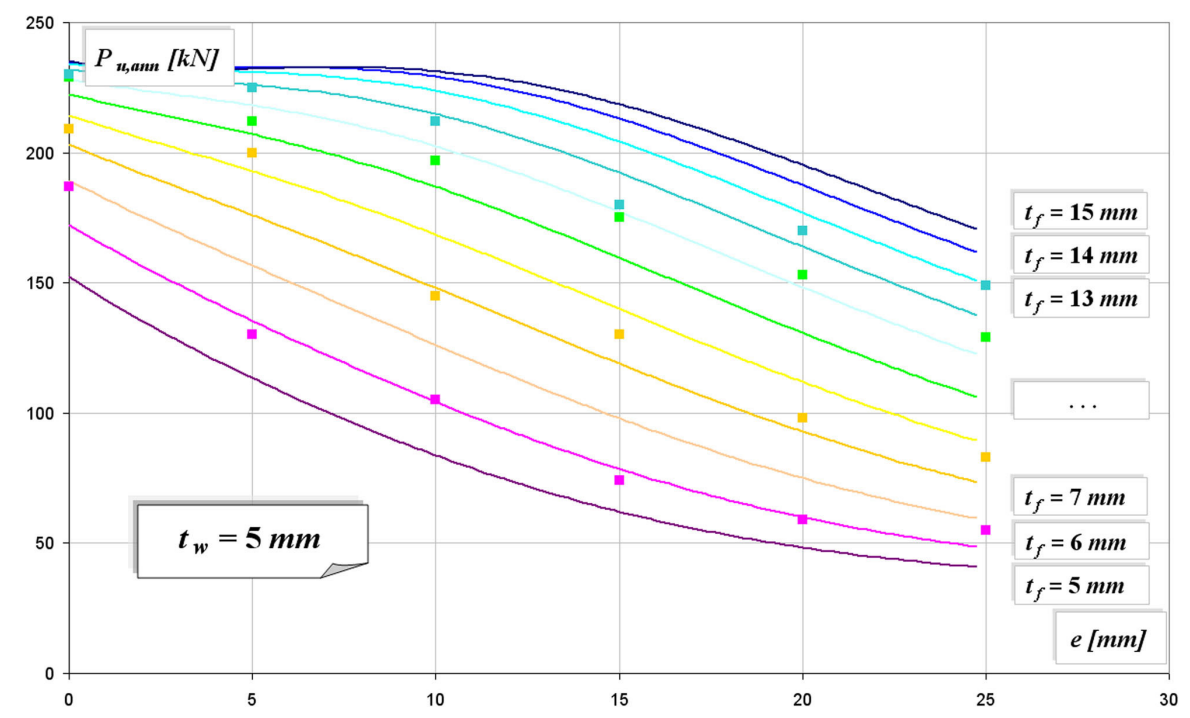

Figure 8. Estimation of collapse load $P_{u, a n n}(e)$ for $t_{w}=5 \mathrm{~mm}$ and $t_{f}=5 \div 15 \mathrm{~mm}$, at c $=50 \mathrm{~mm}, \sigma_{0.2, w}=28 \mathrm{kN} / \mathrm{cm}^{2}$ and $\sigma_{0.2, f}=28 \mathrm{kN} / \mathrm{cm}^{2}$, by means of artificial neural network "c 50 -load $-2-10$ " (square dots present corresponding experimental data for $t_{f}=6,8,10$ and 12 mm) 


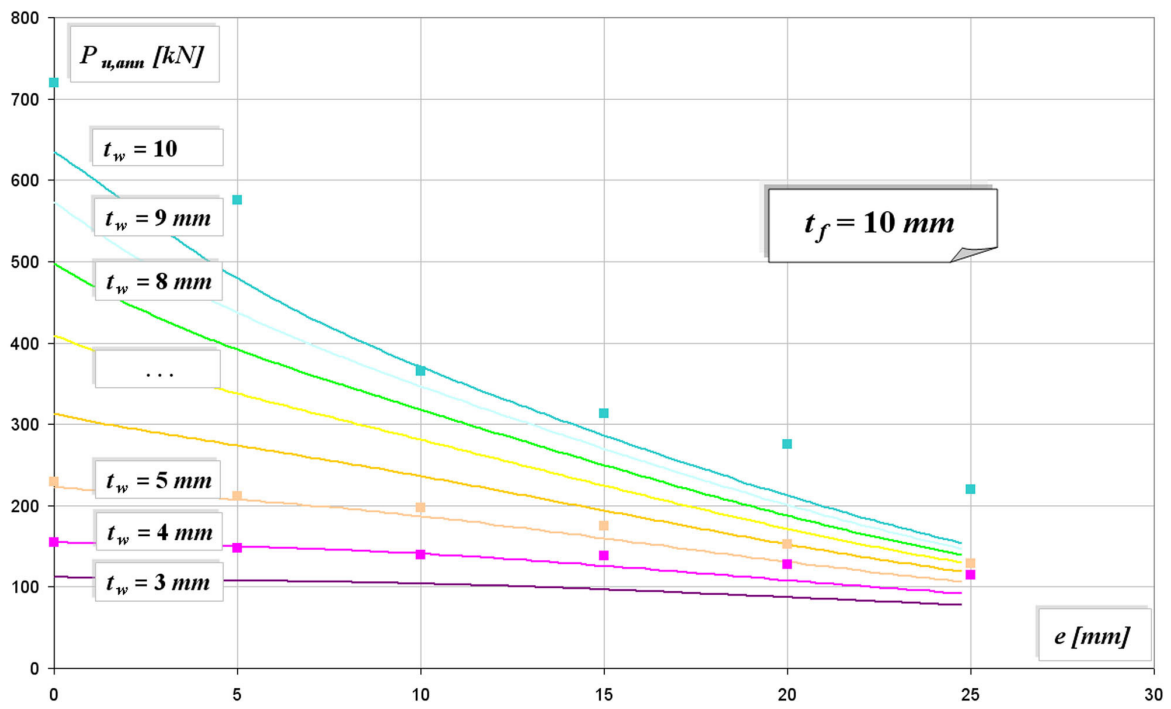

Figure 9. Estimation of collapse load $P_{u, a n n}(e)$ for $t_{f}=10 \mathrm{~mm}$ and $t_{w}=3 \div 10 \mathrm{~mm}$, at $c=50 \mathrm{~mm}, \sigma_{0.2 w}=28 \mathrm{kN} / \mathrm{cm}^{2}$ and $\sigma_{o . f}=28 \mathrm{kN} / \mathrm{cm}^{2}$, by means of artificial neural network "c 50 - load $-2-10$ " (square dots present corresponding experimental data for $t_{w}=4,5$ and $10 \mathrm{~mm}$ )

network training database. Herein that is range of experimental data from 2001 and 2007, Table $1: 1 \leq t_{f} / t_{w} \leq 5,1 / 30 \leq e / b_{f}$ $\leq 1 / 6,70 \leq a / t_{w} \leq 233,10 \leq b_{f} / t_{f} \leq 50, c / a=0.071, a / h_{w}=1$; with constants: $a=h_{w}=700 \mathrm{~mm}, b_{f}=150 \mathrm{~mm}, c=50 \mathrm{~mm}$ and variables: $e(0,5,10,15,20,25 \mathrm{~mm}), t_{f}(3,4,6,8,9,10,12,15$ $\mathrm{mm}), t_{w}(3,4,5,6,8,10 \mathrm{~mm})(8)$.

In order to graphically present validation of ANN results, i.e. match with experimental data, in Figure 8 and 9 experimental results are given as separate dots, in colour of corresponding line which presents ANN forecast model results. Experimental data are those from Table 1 , with real values of mechanical characteristics of material $\sigma_{o .2, w}$ and $\sigma_{o .2, f}$, that may explain slight discrepancy of experimental and ANN results. In Figure 8, experimental data with $t_{w}=5 \mathrm{~mm}$ are inserted: series $\mathrm{EB} \mathrm{V}\left(t_{f}=10 \mathrm{~mm}\right), \mathrm{EB} \mathrm{VII}\left(t_{f}=12 \mathrm{~mm}\right), \mathrm{EB} \mathrm{XVI}\left(t_{f}=6 \mathrm{~mm}\right)$ and EB XVII $\left(t_{f}=8 \mathrm{~mm}\right)$. In Figure 9, experimental data with $t_{f}=10 \mathrm{~mm}$ are inserted: series $\mathrm{EB} \mathrm{V}\left(t_{w}=5 \mathrm{~mm}\right)$, EB VI $\left(t_{w}=10 \mathrm{~mm}\right)$ and $\mathrm{EB} \mathrm{XV}\left(t_{w}=4 \mathrm{~mm}\right)$.

Future experimental work, as well as inclusion of existing FEM data in training/validation data base, providing wider range of data base, will help improving quality of ANN modelling results. Apart from that, even on the existing experimental data base, results might be improved - by different network architecture, by different choice of data for training and validation set or by means of another ANN software. Presented forecast models (Figure 8 and 9) are representatives of set of forecast models of ANN "c5O - load - 2-10" which provides simplicity and confident results for application in engineering practice.

\section{RESULTS COMPARISON AND CONCLUSION}

Assessment of quality of two presented numerical methods for determination of ultimate load (empirical mathematical expressions, represented by Equation [3], Paragraph 2, and ANN forecast models, represented by models of network "c5O - load - 2 - 10", Paragraph 3) has been done by comparing their results with the experimental results.

As summarised in Table 1, comparison is done for set of 120 experimental samples tested in 2001 and 2007. All tested girders have dimensions: $b_{f}=150 \mathrm{~mm}, a=700 \mathrm{~mm}$ and $h_{w}=700 \mathrm{~mm}$. Load length is $c=50 \mathrm{~mm}$. Variables are: $e, t$ and $t_{w}$, as well as dimensionless parameters (e.g. $e / b_{f}, e / t_{f}, e /$ $t_{w}, t_{f} / t_{w}, b_{f} / t_{f}, h_{w} / t_{w}$ etc). Real mechanical characteristics of material $\sigma_{o, w}$ and $\sigma_{o, f}$, obtained by tensile test, are taken into account.

Statistical indicators of methods quality are summarised in Table 2. Graphical interpretation or results dispersions, i.e. discrepancy between experimental and numerical results for both methods is shown in Figure 10.

In both numerical procedures, high difference between experimental and numerical results is observed in girders with same or nearly same flange and web thickness (girders no. 33, 35, 44-48, 68-70, 92-96, 104-108, Table 1 and Figure 10), particularly in case of small eccentricities, when experimental ultimate load highly departs from experimental centric ultimate load (girders no. 44, 45, 68, 69, 104, 105, Table 1 and Figure 10). This is more emphasised in girders with thinner plates, as in series EB VIII, EB XII, Table 1.

Furthermore, in both numerical procedures, high deviation from experimental results happens in girders whose mechanical characteristics of material (flange and web yielding/ ultimate stresses) are not precisely determined, but assumed, as in girders no. 54, 77, 78, 92-96, 104-108, 116, Table 1 and Figure 10. The same happens in girders no. 105-108, 112-114, 118-120, Table 1 and Figure 10, whose mechanical characteristics of material are determined by tensile test, but have significant discrepancy in comparison with average values of mechanical characteristics of material in other girders. Difference between experimental and numerical results due to mechanical characteristics of material is more prominent in empirical expression than in ANN forecast model. The explanation is in fact that mechanical characteristics of material do not figure in empirical expression, but are considered in ANN forecast model. Hence, the empirical expression does not account with the difference in mechanical characteristics of centrically and eccentrically loaded girders, as really happened in analysed girders and as was taken into account by ANN forecast models. 
Table 1. Summary of experimental and numerical results - girder characteristics $\left(t_{w}, t_{f}, e, \sigma_{0.2, w}\right.$ and $\left.\sigma_{o .2, f}\right)$, experimental $\left(P_{u, e x p}\right)$ and numerical $\left(P_{u, n u m}: P_{u, e m p}\right.$, by equation [3], or $P_{u, a n n}$, by "c5o - load $-2-10$ ") ultimate loads and comparison parameters $\left(\Delta_{\text {num }}=\left|P_{u, \text { num }}-P_{u, \text { exp }}\right| / P_{u, \text { exp }} ; X_{\text {num }}=P_{u, \text { num }} / P_{u, \text { exp }}\right)$.

\begin{tabular}{|c|c|c|c|c|c|c|c|c|c|c|c|c|c|}
\hline No & Girder & $\begin{array}{c}\boldsymbol{t}_{\boldsymbol{w}} \\
{[\mathrm{mm}]}\end{array}$ & $\begin{array}{c}\boldsymbol{t}_{\boldsymbol{f}} \\
{[\mathrm{mm}]}\end{array}$ & $\begin{array}{c}\boldsymbol{e} \\
{[\mathrm{mm}]}\end{array}$ & $\begin{array}{c}\boldsymbol{\sigma}_{\mathbf{o . 2}, \boldsymbol{w}} \\
{\left[\mathrm{kN} / \mathrm{cm}^{2}\right]}\end{array}$ & $\begin{array}{c}\boldsymbol{\sigma}_{\mathbf{o . 2 , f} \boldsymbol{f}} \\
{\left[\mathrm{kN} / \mathrm{cm}^{2}\right]}\end{array}$ & $\begin{array}{l}\boldsymbol{P}_{\boldsymbol{u}, \boldsymbol{e x p}} \\
{[\mathrm{kN}]}\end{array}$ & $\begin{array}{c}\boldsymbol{P}_{\text {u,emp }} \\
{[\mathrm{kN}]}\end{array}$ & $\begin{array}{c}\Delta_{\text {emp }} \\
{[\%]}\end{array}$ & $\boldsymbol{X}_{\text {emp }}$ & $\begin{array}{l}\boldsymbol{P}_{u, \boldsymbol{a n n}} \\
{[\mathrm{kN}]}\end{array}$ & $\begin{array}{c}\Delta_{a n n} \\
{[\%]}\end{array}$ & $\boldsymbol{X}_{a n n}$ \\
\hline 1 & $E B I-1$ & 3.03 & 14.75 & 0 & 32.73 & 26.87 & 133 & 133 & 0.0 & 1.00 & 136 & 2.3 & 1.02 \\
\hline 2 & $E B I-2$ & 3.03 & 14.72 & 5 & 32.73 & 26.87 & 128 & 133 & 3.9 & 1.04 & 129 & 0.8 & 1.01 \\
\hline 3 & $E B$ I - 3 & 3.03 & 14.77 & 10 & 32.73 & 26.87 & 127 & 133 & 4.7 & 1.05 & 131 & 3.1 & 1.03 \\
\hline 4 & $E B I-4$ & 3.03 & 14.74 & 15 & 32.73 & 26.87 & 135 & 133 & 1.5 & 0.99 & 134 & 0.7 & 0.99 \\
\hline 5 & EB I - 5 & 3.04 & 14.81 & 20 & 32.73 & 26.87 & 134 & 133 & 0.7 & 0.99 & 134 & 0.0 & 1.00 \\
\hline 6 & EB I - 6 & 3.04 & 14.80 & 25 & 32.73 & 26.87 & 124 & 123 & 0.5 & 0.99 & 125 & 0.8 & 1.01 \\
\hline 7 & $E B$ II - 1 & 5.95 & 14.71 & 0 & 30.93 & 26.87 & 340 & 340 & 0.0 & 1.00 & 339 & 0.3 & 1.00 \\
\hline 8 & EB II - 2 & 5.95 & 14.78 & 5 & 30.93 & 26.87 & 320 & 322 & 0.5 & 1.00 & 325 & 1.6 & 1.02 \\
\hline 9 & $E B I I-3$ & 5.97 & 14.73 & 10 & 30.93 & 26.87 & 326 & 296 & 9.1 & 0.91 & 311 & 4.6 & 0.95 \\
\hline 10 & EB II - 4 & $5 \cdot 97$ & 14.71 & 15 & 30.93 & 26.87 & 296 & 269 & 9.0 & 0.91 & 280 & 5.4 & 0.95 \\
\hline 11 & EB II - 5 & 6.00 & 14.78 & 20 & 30.93 & 26.87 & 243 & 241 & 0.9 & 0.99 & 238 & 2.1 & 0.98 \\
\hline 12 & EB II - 6 & 6.00 & 14.81 & 25 & 30.93 & 26.87 & 197 & 210 & 6.8 & 1.07 & 192 & 2.5 & 0.97 \\
\hline 13 & $E B$ III - 1 & 5.95 & 14.78 & 0 & 30.93 & 26.87 & 342 & 342 & 0.0 & 1.00 & 339 & 0.9 & 0.99 \\
\hline 14 & EB III - 2 & 5.95 & 14.80 & 5 & 30.93 & 26.87 & 321 & 324 & 0.9 & 1.01 & 324 & 0.9 & 1.01 \\
\hline 15 & $E B I I I-3$ & 6.01 & 14.81 & 10 & 30.93 & 26.87 & 301 & 298 & 1.0 & 0.99 & 314 & $4 \cdot 3$ & 1.04 \\
\hline 16 & EB III - 4 & 6.01 & 14.79 & 15 & 30.93 & 26.87 & 267 & 271 & 1.3 & 1.01 & 282 & 5.6 & 1.06 \\
\hline 17 & $E B I I I-5$ & 6.02 & 14.78 & 20 & 30.93 & 26.87 & 228 & 242 & 6.1 & 1.06 & 239 & 4.8 & 1.05 \\
\hline 18 & EB III - 6 & 6.02 & 14.81 & 25 & 30.93 & 26.87 & 187 & 211 & 12.7 & 1.13 & 193 & 3.2 & 1.03 \\
\hline 19 & $E B I V-1$ & 7.98 & 14.83 & 0 & 26.24 & 26.87 & 401 & 401 & 0.0 & 1.00 & 495 & 23.4 & 1.23 \\
\hline 20 & $E B I V-2$ & 7.98 & 14.77 & 5 & 26.24 & 26.87 & 418 & 349 & 16.6 & 0.83 & 420 & 0.5 & 1.00 \\
\hline 21 & $E B I V-3$ & 7.98 & 14.78 & 10 & 26.24 & 26.87 & 394 & 300 & 23.9 & 0.76 & 363 & 7.9 & 0.92 \\
\hline 22 & $E B I V-4$ & 7.98 & 14.77 & 15 & 26.24 & 26.87 & 301 & 259 & 14.1 & 0.86 & 303 & 0.7 & 1.01 \\
\hline 23 & $E B I V-5$ & 7.97 & 14.77 & 20 & 26.24 & 26.87 & 245 & 224 & 8.6 & 0.91 & 244 & 0.4 & 1.00 \\
\hline 24 & $E B I V-6$ & 7.97 & 14.77 & 25 & 26.24 & 26.87 & 209 & 198 & 5.2 & 0.95 & 195 & 6.7 & 0.93 \\
\hline 25 & $E B V-1$ & 5.08 & 10.28 & 0 & 27.09 & 30.97 & 229 & 229 & 0.0 & 1.00 & 232 & 1.3 & 1.01 \\
\hline 26 & $E B V-2$ & 5.08 & 10.35 & 5 & 27.09 & 30.97 & 212 & 205 & $3 \cdot 4$ & 0.97 & 212 & 0.0 & 1.00 \\
\hline 27 & $E B V-3$ & 5.10 & 10.26 & 10 & 27.09 & 30.97 & 197 & 179 & 9.0 & 0.91 & 196 & 0.5 & 0.99 \\
\hline 28 & $E B V-4$ & 5.10 & 10.26 & 15 & 27.09 & 30.97 & 175 & 157 & 10.2 & 0.90 & 176 & 0.6 & 1.01 \\
\hline 29 & $E B V-5$ & 5.12 & 10.25 & 20 & 27.09 & 30.97 & 153 & 138 & 9.8 & 0.90 & 154 & 0.7 & 1.01 \\
\hline 30 & $E B V-6$ & 5.12 & 10.29 & 25 & 27.09 & 30.97 & 129 & 122 & 5.5 & 0.95 & 134 & 3.9 & 1.04 \\
\hline 31 & $E B V I-1$ & 10.33 & 10.29 & 0 & 30.97 & 30.97 & 720 & 720 & 0.0 & 1.00 & 701 & 2.6 & 0.97 \\
\hline 32 & $E B$ VI - 2 & 10.33 & 10.27 & 5 & 30.97 & 30.97 & 575 & 553 & 3.9 & 0.96 & 579 & 0.7 & 1.01 \\
\hline 33 & $E B V I-3$ & 10.23 & 10.21 & 10 & 30.97 & 30.97 & 365 & 414 & 13.5 & 1.13 & 430 & 17.8 & 1.18 \\
\hline 34 & EB VI - 4 & 10.23 & 10.22 & 15 & 30.97 & 30.97 & 313 & 313 & 0.1 & 1.00 & 342 & 9.3 & 1.09 \\
\hline 35 & $E B$ VI - 5 & 10.26 & 10.24 & 20 & 30.97 & 30.97 & 275 & 245 & 11.0 & 0.89 & 276 & 0.4 & 1.00 \\
\hline 36 & $E B V I-6$ & 10.26 & 10.23 & 25 & 30.97 & 30.97 & 220 & 213 & 3.4 & 0.97 & 217 & 1.4 & 0.99 \\
\hline 37 & $E B$ VII - 1 & 4.98 & 12.20 & 0 & 27.09 & 28.88 & 230 & 230 & 0.0 & 1.00 & 227 & 1.3 & 0.99 \\
\hline 38 & $E B$ VII - 2 & 4.98 & 12.21 & 5 & 27.09 & 28.88 & 225 & 217 & 3.6 & 0.96 & 220 & 2.2 & 0.98 \\
\hline 39 & EB VII - 3 & 5.11 & 12.19 & 10 & 27.09 & 28.88 & 212 & 197 & 7.0 & 0.93 & 218 & 2.8 & 1.03 \\
\hline 40 & EB VII - 4 & 5.11 & 12.19 & 15 & 27.09 & 28.88 & 180 & 179 & 0.7 & 0.99 & 196 & 8.9 & 1.09 \\
\hline 41 & EB VII - 5 & 5.02 & 12.17 & 20 & 27.09 & 28.88 & 170 & 162 & 5.0 & 0.95 & 167 & 1.8 & 0.98 \\
\hline 42 & EB VII - 6 & 5.02 & 12.19 & 25 & 27.09 & 28.88 & 149 & 141 & 5.2 & 0.95 & 144 & 3.4 & 0.97 \\
\hline 43 & $E B$ VIII - 1 & 2.98 & 3.05 & 0 & 27.44 & 27.44 & 79 & 79 & 0.0 & 1.00 & 72 & 8.9 & 0.91 \\
\hline 44 & $E B$ VIII - 2 & 2.98 & 2.98 & 5 & 27.44 & 27.44 & 44 & 60 & $37 \cdot 3$ & 1.37 & 52 & 18.2 & 1.18 \\
\hline 45 & EB VIII - 3 & 2.98 & 2.99 & 10 & 27.44 & 27.44 & 37 & 45 & 22.0 & 1.22 & 40 & 8.1 & 1.08 \\
\hline 46 & EB VIII - 4 & 2.98 & 3.05 & 15 & 27.44 & 27.44 & 29 & 34 & 18.1 & 1.18 & 34 & 17.2 & 1.17 \\
\hline 47 & EB VIII - 5 & 3.08 & 2.97 & 20 & 27.44 & 27.44 & 23 & 26 & 12.0 & 1.12 & 31 & 34.8 & 1.35 \\
\hline
\end{tabular}

$\left({ }^{*}\right.$ - Values are not obtained by tensile test, but estimated as average of $\sigma_{o .2}$ values for other plate thicknesses, determined by tensile tests.

blue highlight $\quad$ - discrepancy $>11 \%$, i.e. $11 \%<\Delta_{\text {num }} \leq 20 \%$;

yellow highlight $\quad-$ discrepancy $>20 \%$, i.e. $20 \%<\Delta_{\text {num }} \leq 30 \%$;

red highlight $\quad$ - discrepancy $\Delta_{\text {num }}>30 \%$;

grey highlight $\quad$ - significant discrepancy for centric load.) 


\begin{tabular}{|c|c|c|c|c|c|c|c|c|c|c|c|c|c|}
\hline No & Girder & $\begin{array}{c}\boldsymbol{t}_{\boldsymbol{w}} \\
{[\mathrm{mm}]}\end{array}$ & $\begin{array}{c}\boldsymbol{t}_{\boldsymbol{f}} \\
{[\mathrm{mm}]}\end{array}$ & $\begin{array}{c}\boldsymbol{e} \\
{[\mathrm{mm}]}\end{array}$ & $\begin{array}{c}\boldsymbol{\sigma}_{\mathbf{0 . 2}, \boldsymbol{w}} \\
{\left[\mathrm{kN} / \mathrm{cm}^{2}\right]}\end{array}$ & $\begin{array}{c}\boldsymbol{\sigma}_{\mathbf{o . 2 , f} \boldsymbol{f}} \\
{\left[\mathrm{kN} / \mathrm{cm}^{2}\right]}\end{array}$ & $\begin{array}{l}\boldsymbol{P}_{\boldsymbol{u}, \boldsymbol{e x p}} \\
{[\mathrm{kN}]}\end{array}$ & $\begin{array}{c}\boldsymbol{P}_{\boldsymbol{u}, \boldsymbol{e m p} \boldsymbol{p}} \\
{[\mathrm{kN}]}\end{array}$ & $\begin{array}{c}\Delta_{\text {emp }} \\
{[\%]}\end{array}$ & $\boldsymbol{X}_{\text {emp }}$ & $\begin{array}{c}\boldsymbol{P}_{\boldsymbol{u}, \boldsymbol{a n n}} \\
{[\mathrm{kN}]}\end{array}$ & $\begin{array}{c}\Delta_{a n n} \\
{[\%]}\end{array}$ & $\boldsymbol{X}_{a n n}$ \\
\hline 48 & EB VIII - 6 & 3.08 & 3.00 & 25 & 27.44 & 27.44 & 20 & 23 & 13.8 & 1.14 & 29 & 45.0 & 1.45 \\
\hline 49 & $E B I X-1$ & 3.01 & 5.69 & 0 & 27.44 & $28.73^{(*)}$ & 95 & 95 & 0.0 & 1.00 & 105 & 10.5 & 1.11 \\
\hline 50 & $E B I X-2$ & 3.01 & $5 \cdot 77$ & 5 & 27.44 & $28.73^{(*)}$ & 80 & 83 & 4.4 & 1.04 & 88 & 10.0 & 1.10 \\
\hline 51 & $E B I X-3$ & 3.00 & 5.72 & 10 & 27.44 & $28.73^{(*)}$ & 69 & 72 & 4.6 & 1.05 & 72 & $4 \cdot 3$ & 1.04 \\
\hline 52 & $E B I X-4$ & 3.00 & 5.70 & 15 & 27.44 & $28.73^{(*)}$ & 57 & 63 & 9.7 & 1.10 & 57 & 0.0 & 1.00 \\
\hline 53 & $E B I X-5$ & 3.26 & 5.76 & 20 & 27.44 & $28.73^{(*)}$ & 47 & 51 & 9.3 & 1.09 & 49 & $4 \cdot 3$ & 1.04 \\
\hline 54 & $E B I X-6$ & 3.26 & 5.68 & 25 & 27.44 & $28.73^{(*)}$ & 39 & 45 & 14.8 & 1.15 & 41 & 5.1 & 1.05 \\
\hline 55 & $E B X-1$ & 2.98 & 8.92 & 0 & 27.44 & 28.20 & 102 & 102 & 0.0 & 1.00 & 110 & 7.8 & 1.08 \\
\hline 56 & $E B X-2$ & 2.98 & 9.04 & 5 & 27.44 & 28.20 & 105 & 102 & 2.9 & 0.97 & 104 & 1.0 & 0.99 \\
\hline 57 & $E B \boldsymbol{X}-\boldsymbol{3}$ & 3.02 & 8.92 & 10 & 27.44 & 28.20 & 107 & 99 & 7.5 & 0.92 & 97 & 9.3 & 0.91 \\
\hline 58 & $E B X-4$ & 3.02 & 8.97 & 15 & 27.44 & 28.20 & 90 & 93 & 3.5 & 1.04 & 88 & 2.2 & 0.98 \\
\hline 59 & $E B X-5$ & 2.97 & 8.93 & 20 & 27.44 & 28.20 & 85 & 86 & 1.0 & 1.01 & 76 & 10.6 & 0.89 \\
\hline 60 & $E B X-6$ & 2.97 & 8.89 & 25 & 27.44 & 28.20 & 70 & 74 & 6.2 & 1.06 & 66 & $5 \cdot 7$ & 0.94 \\
\hline 61 & $E B X I-1$ & 2.97 & 12.17 & o & 27.44 & 28.88 & 116 & 116 & 0.0 & 1.00 & 112 & 3.4 & 0.97 \\
\hline 62 & $E B X I-2$ & 2.97 & 12.12 & 5 & 27.44 & 28.88 & 113 & 116 & 2.7 & 1.03 & 109 & 3.5 & 0.96 \\
\hline 63 & $E B X I-3$ & 3.05 & 12.17 & 10 & 27.44 & 28.88 & 115 & 116 & 0.9 & 1.01 & 114 & 0.9 & 0.99 \\
\hline 64 & $E B X I-4$ & 3.05 & 12.18 & 15 & 27.44 & 28.88 & 110 & 116 & 5.5 & 1.05 & 114 & 3.6 & 1.04 \\
\hline 65 & $E B X I-5$ & 3.03 & 12.17 & 20 & 27.44 & 28.88 & 105 & 116 & 10.5 & 1.10 & 110 & 4.8 & 1.05 \\
\hline 66 & $E B X I-6$ & 3.03 & 12.19 & 25 & 27.44 & 28.88 & 115 & 100 & 12.9 & 0.87 & 105 & 8.7 & 0.91 \\
\hline 67 & $E B X I I-1$ & 3.88 & 3.88 & o & 28.50 & 28.50 & 120 & 120 & 0.0 & 1.00 & 110 & 8.3 & 0.92 \\
\hline 68 & $E B X I I-2$ & 3.88 & 3.86 & 5 & 28.50 & 28.50 & 70 & 92 & 31.0 & 1.31 & 80 & 14.3 & 1.14 \\
\hline 69 & $E B$ XII - 3 & $3 \cdot 91$ & 3.93 & 10 & 28.50 & 28.50 & 50 & 69 & 37.3 & 1.37 & 60 & 20.0 & 1.20 \\
\hline 70 & $E B$ XII - 4 & 3.91 & 3.95 & 15 & 28.50 & 28.50 & 45 & 52 & 14.9 & 1.15 & 46 & 2.2 & 1.02 \\
\hline 71 & $E B X I I-5$ & 3.95 & 3.92 & 20 & 28.50 & 28.50 & 40 & 40 & 0.1 & 1.00 & 38 & 5.0 & 0.95 \\
\hline 72 & $E B$ XII - 6 & 3.95 & 3.93 & 25 & 28.50 & 28.50 & 35 & 35 & 0.5 & 1.01 & 34 & 2.9 & 0.97 \\
\hline 73 & $E B$ XIII - 1 & 3.87 & 5.69 & o & 28.50 & $28.73^{(*)}$ & 125 & 125 & 0.0 & 1.00 & 133 & 6.4 & 1.06 \\
\hline 74 & $E B$ XIII - 2 & 3.87 & 5.69 & 5 & 28.50 & $28.73^{(*)}$ & 110 & 103 & 6.4 & 0.94 & 107 & 2.7 & 0.97 \\
\hline 75 & EB XIII - 3 & 3.87 & 5.69 & 10 & 28.50 & $28.73^{(*)}$ & 86 & 84 & 2.5 & 0.97 & 85 & 1.2 & 0.99 \\
\hline 76 & EB XIII - 4 & 3.87 & 5.71 & 15 & 28.50 & $28.73^{(*)}$ & 68 & 69 & 1.7 & 1.02 & 66 & 2.9 & 0.97 \\
\hline 77 & EB XIII - 5 & 3.87 & 5.80 & 20 & 28.50 & $28.73^{(*)}$ & 50 & 59 & 17.9 & 1.18 & 54 & 8.0 & 1.08 \\
\hline 78 & EB XIII - 6 & 3.87 & 5.67 & 25 & 28.50 & $28.73^{(*)}$ & 45 & 51 & 13.7 & 1.14 & 44 & 2.2 & 0.98 \\
\hline 79 & $E B X I V-1$ & 3.89 & 8.07 & 0 & 28.50 & 30.03 & 140 & 140 & 0.0 & 1.00 & 150 & 7.1 & 1.07 \\
\hline 80 & $E B X I V-2$ & 3.89 & 8.14 & 5 & 28.50 & 30.03 & 129 & 126 & 2.3 & 0.98 & 136 & 5.4 & 1.05 \\
\hline 81 & $E B X I V-3$ & 3.93 & 8.22 & 10 & 28.50 & 30.03 & 130 & 112 & 13.9 & 0.86 & 125 & 3.8 & 0.96 \\
\hline 82 & $E B X I V-4$ & 3.93 & 8.21 & 15 & 28.50 & 30.03 & 100 & 99 & 1.3 & 0.99 & 110 & 10.0 & 1.10 \\
\hline 83 & $E B X I V-5$ & 3.91 & 8.08 & 20 & 28.50 & 30.03 & 86 & 86 & 0.4 & 1.00 & 92 & 7.0 & 1.07 \\
\hline 84 & $E B X I V-6$ & 3.91 & 8.19 & 25 & 28.50 & 30.03 & 75 & 77 & 2.4 & 1.02 & 80 & 6.7 & 1.07 \\
\hline 85 & $E B X V-1$ & 3.91 & 10.13 & o & 28.50 & 30.97 & 155 & 155 & 0.0 & 1.00 & 153 & 1.3 & 0.99 \\
\hline 86 & $E B X V-2$ & 3.91 & 10.19 & 5 & 28.50 & 30.97 & 148 & 149 & 0.7 & 1.01 & 146 & 1.4 & 0.99 \\
\hline 87 & $E B X V-3$ & 3.93 & 10.22 & 10 & 28.50 & 30.97 & 140 & 139 & 0.4 & 1.00 & 143 & 2.1 & 1.02 \\
\hline 88 & $E B X V-4$ & 3.93 & 10.34 & 15 & 28.50 & 30.97 & 138 & 129 & 6.3 & 0.94 & 137 & 0.7 & 0.99 \\
\hline 89 & $E B X V-5$ & 3.90 & 10.19 & 20 & 28.50 & 30.97 & 128 & 115 & 9.8 & 0.90 & 123 & 3.9 & 0.96 \\
\hline 90 & $E B X V-6$ & 3.90 & 10.17 & 25 & 28.50 & 30.97 & 115 & 101 & 12.3 & 0.88 & 111 & 3.5 & 0.97 \\
\hline 91 & $E B X V I-1$ & 5.01 & 5.75 & 0 & 27.09 & $28.73^{(*)}$ & 187 & 187 & 0.0 & 1.00 & 172 & 8.0 & 0.92 \\
\hline 92 & $E B X V I-2$ & 5.01 & 5.74 & 5 & 27.09 & $28.73^{(*)}$ & 130 & 146 & 12.6 & 1.13 & 135 & 3.8 & 1.04 \\
\hline 93 & $E B X V I-3$ & 4.95 & $5 \cdot 71$ & 10 & 27.09 & $28.73^{(*)}$ & 105 & 113 & 7.8 & 1.08 & 103 & 1.9 & 0.98 \\
\hline 94 & $E B X V I-4$ & 4.95 & $5 \cdot 72$ & 15 & 27.09 & $28.73^{(*)}$ & 74 & 88 & 19.5 & 1.20 & 79 & 6.8 & 1.07 \\
\hline 95 & $E B X V I-5$ & 4.97 & 5.70 & 20 & 27.09 & $28.73^{(*)}$ & 59 & 70 & 19.4 & 1.19 & 61 & 3.4 & 1.03 \\
\hline 96 & $E B X V I-6$ & 4.97 & 5.62 & 25 & 27.09 & $28.73^{(*)}$ & 55 & 61 & 11.4 & 1.11 & 49 & 10.9 & 0.89 \\
\hline 97 & EB XVII - 1 & 5.04 & 8.14 & $\mathrm{o}$ & 27.09 & 30.03 & 209 & 209 & 0.0 & 1.00 & 212 & 1.4 & 1.01 \\
\hline
\end{tabular}

(* - Values are not obtained by tensile test, but estimated as average of $\sigma_{o .2}$ values for other plate thicknesses, determined by tensile tests.

\footnotetext{
blue highlight $\quad$ - discrepancy $>11 \%$, i.e. $11 \%<\Delta_{\text {num }} \leq 20 \%$;

yellow highlight - discrepancy $>20 \%$, i.e. $20 \%<\Delta_{\text {num }} \leq 30 \%$;

red highlight - discrepancy $\Delta_{\text {num }}>30 \%$;

grey highlight $\quad$ - significant discrepancy for centric load.)
} 


\begin{tabular}{|c|c|c|c|c|c|c|c|c|c|c|c|c|c|}
\hline No & Girder & $\begin{array}{c}\boldsymbol{t}_{\boldsymbol{w}} \\
{[\mathrm{mm}]}\end{array}$ & $\begin{array}{c}\boldsymbol{t}_{\boldsymbol{f}} \\
{[\mathrm{mm}]}\end{array}$ & $\begin{array}{c}\boldsymbol{e} \\
{[\mathrm{mm}]}\end{array}$ & $\begin{array}{c}\boldsymbol{\sigma}_{\mathbf{0 . 2}, \boldsymbol{w}} \\
{\left[\mathrm{kN} / \mathrm{cm}^{2}\right]}\end{array}$ & $\begin{array}{c}\boldsymbol{\sigma}_{\mathbf{o . 2 , f} \boldsymbol{f}} \\
{\left[\mathrm{kN} / \mathrm{cm}^{2}\right]}\end{array}$ & $\begin{array}{l}\boldsymbol{P}_{u, \exp } \\
{[\mathrm{kN}]}\end{array}$ & $\begin{array}{c}\boldsymbol{P}_{\text {u,emp }} \\
{[\mathrm{kN}]}\end{array}$ & $\begin{array}{c}\Delta_{e m p} \\
{[\%]}\end{array}$ & $\boldsymbol{X}_{e m p}$ & $\begin{array}{c}\boldsymbol{P}_{\text {u,ann }} \\
{[\mathrm{kN}]}\end{array}$ & $\begin{array}{c}\Delta_{a n n} \\
{[\%]}\end{array}$ & $X_{a n n}$ \\
\hline 98 & $E B X V I I-2$ & 5.04 & 8.21 & 5 & 27.09 & 30.03 & 200 & 176 & 11.8 & 0.88 & 186 & 7.0 & 0.93 \\
\hline 99 & $E B X V I I-3$ & 4.98 & 8.12 & 10 & 27.09 & 30.03 & 145 & 147 & 1.3 & 1.01 & 159 & 9.7 & 1.10 \\
\hline 100 & $E B X V I I-4$ & 4.98 & 8.13 & 15 & 27.09 & 30.03 & 130 & 123 & 5.0 & 0.95 & 136 & 4.6 & 1.05 \\
\hline 101 & $E B X V I I-5$ & 4.96 & 8.08 & 20 & 27.09 & 30.03 & 98 & 105 & 7.6 & 1.08 & 112 & 14.3 & 1.14 \\
\hline 102 & EB XVII - 6 & 4.96 & 8.12 & 25 & 27.09 & 30.03 & 83 & 94 & 12.8 & 1.13 & 93 & 12.0 & 1.12 \\
\hline 103 & $E B X V I I I-1$ & 5.75 & $5 \cdot 73$ & o & $28.73^{(*)}$ & $28.73^{(*)}$ & 335 & 335 & 0.0 & 1.00 & 217 & 35.2 & 0.65 \\
\hline 104 & EB XVIII - 2 & 5.75 & $5 \cdot 75$ & 5 & $28.73^{(*)}$ & $28.73^{(*)}$ & 200 & 257 & 28.6 & 1.29 & 166 & 17.0 & 0.83 \\
\hline 105 & EB XVIII - 3 & 5.99 & $5 \cdot 71$ & 10 & 45.83 & $28.73^{(*)}$ & 130 & 189 & $45 \cdot 3$ & 1.45 & 129 & 0.8 & 0.99 \\
\hline 106 & EB XVIII - 4 & 5.99 & 5.73 & 15 & 45.83 & $28.73^{(*)}$ & 104 & 140 & $34 \cdot 3$ & 1.34 & 99 & 4.8 & 0.95 \\
\hline 107 & EB XVIII - 5 & 6.04 & 5.73 & 20 & 45.83 & $28.73^{(*)}$ & 88 & 109 & 23.6 & 1.24 & 82 & 6.8 & 0.93 \\
\hline 108 & EB XVIII - 6 & 6.04 & 5.72 & 25 & 45.83 & $28.73^{(*)}$ & 69 & 94 & 36.9 & 1.37 & 70 & 1.4 & 1.01 \\
\hline 109 & $E B$ XIX - 1 & 5.99 & 8.83 & 0 & 45.83 & 28.20 & 330 & 330 & 0.0 & 1.00 & 330 & 0.0 & 1.00 \\
\hline 110 & $E B X I X-2$ & 5.99 & 8.96 & 5 & 45.83 & 28.20 & 285 & 274 & 3.8 & 0.96 & 260 & 8.8 & 0.91 \\
\hline 111 & $E B$ XIX -3 & 6.07 & 8.97 & 10 & 45.83 & 28.20 & 217 & 224 & $3 \cdot 4$ & 1.03 & 204 & 6.0 & 0.94 \\
\hline 112 & $E B X I X-4$ & 6.07 & 8.97 & 15 & 45.83 & 28.20 & 155 & 185 & 19.5 & 1.19 & 158 & 1.9 & 1.02 \\
\hline 113 & $E B X I X-5$ & 5.97 & 8.95 & 20 & 45.83 & 28.20 & 125 & 155 & $24 \cdot 3$ & 1.24 & 125 & 0.0 & 1.00 \\
\hline 114 & $E B X I X-6$ & 5.97 & 8.87 & 25 & 45.83 & 28.20 & 107 & 138 & 29.2 & 1.29 & 104 & 2.8 & 0.97 \\
\hline 115 & $E B X X-1$ & 5.67 & 12.14 & 0 & $28.73^{(*)}$ & 28.88 & 395 & 395 & 0.0 & 1.00 & 302 & 23.5 & 0.76 \\
\hline 116 & $E B X X-2$ & 5.67 & 12.13 & 5 & $28.73^{(*)}$ & 28.88 & 365 & 358 & 1.9 & 0.98 & 279 & 23.6 & 0.76 \\
\hline 117 & $E B X X-3$ & 6.00 & 12.21 & 10 & 45.83 & 28.88 & 311 & 311 & 0.1 & 1.00 & 310 & 0.3 & 1.00 \\
\hline 118 & $E B X X-4$ & 6.00 & 12.16 & 15 & 45.83 & 28.88 & 235 & 273 & 16.2 & 1.16 & 253 & 7.7 & 1.08 \\
\hline 119 & $E B X X-5$ & 5.99 & 12.22 & 20 & 45.83 & 28.88 & 202 & 241 & 19.5 & 1.20 & 205 & 1.5 & 1.01 \\
\hline 120 & $E B X X-6$ & 5.99 & 12.17 & 25 & 45.83 & 28.88 & 165 & 212 & 28.7 & 1.29 & 164 & 0.6 & 0.99 \\
\hline
\end{tabular}

${ }^{*}$ - Values are not obtained by tensile test, but estimated as average of $\sigma_{o .2}$ values for other plate thicknesses, determined by tensile tests.

blue highlight $\quad$ - discrepancy $>11 \%$, i.e. $11 \%<\Delta_{\text {num }} \leq 20 \%$;

yellow highlight - discrepancy $>20 \%$, i.e. $20 \%<\Delta_{\text {num }} \leq 30 \%$;

red highlight - discrepancy $\Delta_{\text {num }}>30 \%$;

grey highlight $\quad$ - significant discrepancy for centric load.)

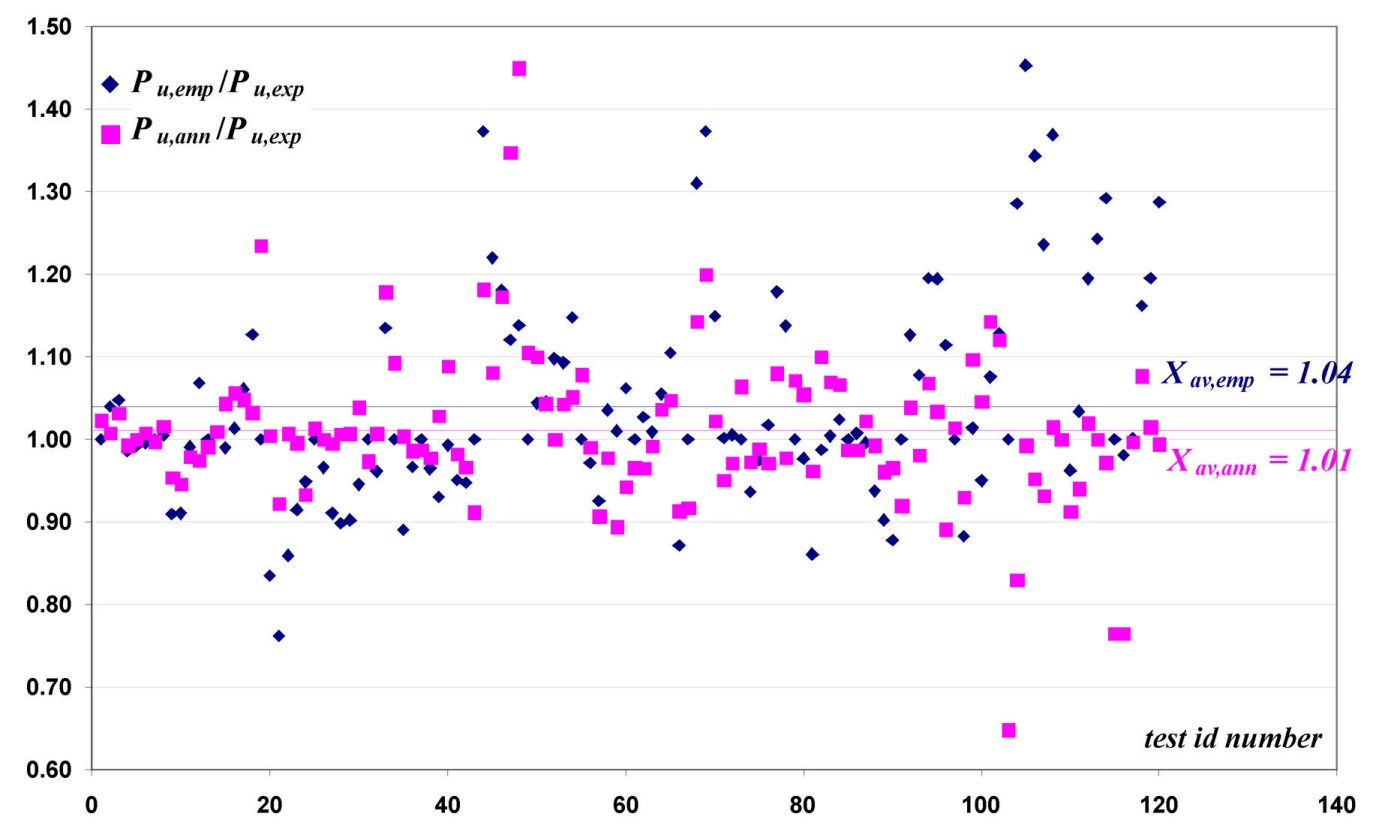

Figure 10. Ratios $P_{u, \text { emp }} / P_{u, e x p}$ and $P_{u, a n n} / P_{u, e x p}$ for tested girders and their average values $X_{a v, e m p}$ and $X_{a v, a n n}$ 
Table 2. Statistical parameters as indicators of quality of numerical methods for determination of $P_{u}$.

\begin{tabular}{|c|c|c|}
\hline Parameter & $\begin{array}{c}\text { empirical expression } \\
\text { Equation [3] }\end{array}$ & $\begin{array}{l}\text { ANN "c5o-load }-2-10 " \\
\text { forecast model }\end{array}$ \\
\hline$\Delta_{a v}\left[\Delta_{a v}=\frac{\sum_{i=1}^{n} \Delta_{i}}{n}, \quad \Delta_{i}=\frac{\left|P_{u, \text { num }}-P_{u, \exp }\right|}{P_{u, \exp }}\right]$ & $8.49 \%$ & $6.06 \%(4.77 \%)^{(\#)}$ \\
\hline$X_{a v} \quad\left[X_{a v}=\frac{\sum_{i=1}^{n} X_{i}}{n}, \quad X_{i}=\frac{P_{u, n u m}}{P_{u, \exp }}\right]$ & 1.04 & $1.01(1.01)$ \\
\hline$S\left[S=\sqrt{\left.\frac{\sum_{i=1}^{n}\left(X_{i}-X_{a v}\right)^{2}}{n}\right]}\right.$ & $12.34 \%$ & $9.47 \%(8.08 \%)$ \\
\hline$V \quad\left[V=\frac{S}{X_{a v}}\right]$ & $11.86 \%$ & $9.37 \%(7.07 \%)$ \\
\hline
\end{tabular}

(\# - Values in brackets are for case when ANN forecast model is used only for $P_{\text {uann }}$ of eccentrically loaded girders, while $P_{u, a n n}$ of centrically loaded girders are not forecasted, but considered to be equal to experimental values, i.e. for centrically loaded girders: $P_{u, a n n}=P_{u, \exp }, \Delta_{i, a n n}=O$ and $X_{i, a n n}=1$, the same as for empirical expression.)

Significant differences ( $>10 \%$ ) between experimental and primarily empirical values in girders no. 18, 20-22, 66, 81, 90, 98, 101, 102, Table 1 and Figure 10, which are not due to upper elaborated reasons, might be explained either by unpredictable and unexpected behaviour of experimentally tested girders, by unavoidable experimental variations (associated with human factors, limitations of available equipment and testing procedure, inherent variability in materials, dimensions etc) or by imperfections of proposed numerical procedures. The same may be said for reasonable results discrepancies of less than $10 \%$, in all the rest girders.

The fact is that presented methods are not exact solutions and deviation of their results is expected. As long as the deviation is up to the acceptable level, approximate solutions may have practical application. In addition, it has to be pointed out that both presented methods are artificial, in a way, purely mathematical procedures not entering the core of girder collapse problem, not explaining the girder collapse, its mechanism and real, physical happenings in girder in the moment of collapse, immediately before and after the collapse moment. The issue of collapse mode and difference between centric and eccentric collapse mode in eccentrically loaded girder is not tackled by any of these two methods. In both methods mathematical apparatus is applied without taking into consideration collapse mode. Hence, both procedures should be considered as a plain tool, useful in engineering practice as well as in scientific research, but without solving problem of definition of collapse mode in eccentrically patch loaded I-girders.
It might be concluded that presented ANN forecast model has better statistical indicators, i.e. dispersion of results is lower than for presented empirical expression. However, presented ANN forecast model has narrower range of database used for its creation than presented empirical expression, i.e. empirical expression is formulated for wider domain of some input parameters $\left(e / b_{f}, a / t_{w}, b_{f} / t_{f}, c / a, a / h_{w}\right)$. It is expected to have higher dispersion of results for wider domain of creation database. Hence, ANN forecast model provides more precise results, but empirical expression provides application in wider domain of input parameters. Recommendation for engineering practice would be to combine both methods.

Generally, both methods have satisfying and acceptable, reliable and confident results, as well as simple practical application. However, it is necessary to be aware and to take care about their limits and domains of reliable application. It is also important to keep in mind that equation [3] and ANN "c5o - load - 2-10" are not final solutions for $P_{u}$ determination. Both methods, ANN modelling and empirical expressions, might and should be improved by future experimental and numerical work.

\section{ACKNOWLEDGMENTS}

Special thanks to Coimbra Group and CGHS (Coimbra Group Hospitality Scheme) programme which enabled cooperation and join research work of scientists from the University of Montenegro and the University of Granada.

\section{REFERENCES}

(1) Elgaaly, M., Nunan, W. (1989). Behavior of rolled section web under eccentric edge compressive loads. Journal of Structural Engineering, 115(7): 1561-1578, doi: http://dx.doi.org/10.1061/(ASCE)0733-9445(1989)115:7(1561).

(2) Elgaaly, M., Salkar, R.K. (1990). Behavior of webs under eccentric compressive edge loads. En IUTAM Symposium, Prague.

(3) Galambos, T.V. (1998). Guide to stability design criteria for metal structures. New York: John Wiley \& Sons, Inc. 
(4) Drdacky, M. (1991). On two particular problems of plate girders webs under partial edge loads. Journal of Constructional Steel Research, 20(3): 183-190, doi: http://dx.doi.org/10.1016/0143-974X(91)90031-U.

(5) Lučić, D. (2001). Experimental Research: Thin-Walled I Girders Subjected to Centric and Eccentric Patch Loading. Experimental Researches, Vol.1. Podgorica: University of Montenegro - Faculty of Civil Engineering.

(6) Lučić, D., Šćepanović, B. (2004). Experimental Investigation on Locally Pressed I-beams Subjected to Eccentric Patch Loading. Journal of Constructional Steel Research, 6o(3-5): 525-534, doi: http://dx.doi.org/10.1016/So143974X(03)00127-5.

(7) Śćepanović, B. (2002). I-girders under eccentric local loading - experimental-theoretical analysis (Master thesis). Belgrade: University of Belgrade.

(8) Šćepanović, B. (2009). Analysis of eccentrically locally loaded steel I-girders (Doctoral thesis). Podgorica: University of Montenegro and University of Granada.

(9) Šćepanović, B., Gil-Martín, L.M., Hernández Montes, E., Aschheim, M., Lučić, D. (2009). Ultimate strength of I-girders under eccentric patch loading: Derivation of a new strength reduction coefficient. Engineering Structures, 31(7): 14031413, doi: http://dx.doi.org/10.1016/j.engstruct.2009.02.005.

(10) Gil Martín, L.M., Šćepanović, B., Hernández-Montes, E., Aschheim, M., Lučić, D. (2010). Eccentrically Patch Loaded Steel I-Girders: Influence of Patch Length on Ultimate Strength. Journal of Constructional Steel Research, 66(5): 716722, doi: http://dx.doi.org/10.1016/j.jcsr.2009.12.012.

(11) Knežević, M. (2004). Risk management during realisation of the civil engineering projects (Doctoral thesis). Belgrade: University of Belgrade.

$$
* * *
$$

